\title{
Lifestyle factors among proton pump inhibitor users and nonusers: a cross-sectional study in a population-based setting
}

This article was published in the following Dove Press journal:

Clinical Epidemiology

3 December 2013

Number of times this article has been viewed

\author{
Frederik Hvid-Jensen' \\ Rikke B Nielsen ${ }^{2}$ \\ Lars Pedersen ${ }^{2}$ \\ Peter Funch-Jensen ${ }^{3}$ \\ Asbjørn Mohr Drewes ${ }^{4}$ \\ Finn B Larsen ${ }^{5}$ \\ Reimar W Thomsen ${ }^{2}$ \\ 'Department of Surgical \\ Gastroenterology L, Aarhus University \\ Hospital, Aarhus, ${ }^{2}$ Department of \\ Clinical Epidemiology, Institute of \\ Clinical Medicine, Aarhus University \\ Hospital, Aarhus, ${ }^{3}$ Institute of \\ Clinical Medicine, Aarhus University \\ Hospital, Aarhus, ${ }^{4}$ Mech-Sense Centre, \\ Department of Gastroenterology, \\ Aarhus University Hospital, \\ Aalborg, ${ }^{5}$ Public Health and Quality \\ Improvement, Central Denmark \\ Region, Denmark
}

Correspondence: Frederik Hvid-Jensen

Department of Surgical

Gastroenterology, Aarhus

University Hospital, Nørrebrogade

44 DK-8000 Aarhus C, Denmark

Email frederikhvid@gmail.com
Purpose: Lifestyle factors may influence observed associations between proton pump inhibitor (PPI) usage and health outcomes. The aim of the study reported here was to examine characteristics and differences in lifestyle among PPI users and nonusers.

Methods: This cross-sectional study utilized data from a 2006 population-based health survey of 21,637 persons in the Central Danish Region. All persons using prescribed PPIs were identified through linkage to a population-based prescription database. Biometric measures and prevalence of smoking, excessive alcohol consumption, diet, and physical exercise were analyzed, comparing PPI users with nonusers.

Results: Among 10,129 (46.8\%) male and 11,508 (53.2\%) female survey respondents, $1,356(13.4 \%)$ males and 1,691 (14.7\%) females reported ever use of PPIs. PPI users were more obese $(16.7 \%)$ than nonusers $(13.1 \%)$, with an age- and sex-standardized prevalence ratio (PR) of 1.3 (95\% confidence interval [CI]: 1.2-1.4). The prevalence of smokers was also higher in the PPI group (26.2\% vs $22.3 \%$ [PR $=1.2,95 \%$ CI: $1.1-1.3])$, as was the prevalence of ex-smokers ( $41.0 \%$ vs $32.0 \%$ [PR $=1.2,95 \% \mathrm{CI}: 1.1-1.2])$. Unhealthy diet was slightly more common among PPI users than among nonusers (15.4\% vs $13.0 \%)$, with a PR of $1.2(95 \%$ CI: 1.1-1.3). Physical exercise level and alcohol consumption were similar in the two groups. Hospital-diagnosed comorbidity was observed in 35\% of PPI users (a Charlson Comorbidity Index score of 1 or more) compared with only $15 \%$ among nonusers.

Conclusion: PPI users are more obese, smoke more, and have significantly more comorbidities than PPI nonusers. These data are important when evaluating unmeasured confounding in observational studies of PPI effects.

Keywords: PPI, obesity, smoking, reflux, population-based, gastroesophageal reflux

\section{Introduction}

After the introduction of proton pump inhibitors (PPIs) more than two decades ago, many studies have documented their beneficial effect in inhibiting gastric acid production. ${ }^{1-5}$ PPIs are now the drugs of choice for treating gastroesophageal reflux disease (GERD), which occurs in $42 \%$ of Westerners on a monthly basis, as well as for treating peptic ulcer disease, Helicobacter pylori infection, and Zollinger-Ellison syndrome. ${ }^{6-9}$ Their treatment effects have been well described, and PPIs are now among the most prescribed drugs in the world. ${ }^{10-16}$

As PPIs are considered generally safe drugs to use, a large percentage of patients is prescribed PPIs without a proper medical indication. ${ }^{17,18}$ However, some observational database studies have suggested an increased risk of adverse events associated with PPI use, including cancer, osteoporosis, fractures, diarrhea, cardiovascular 
events, and pneumonia. ${ }^{19-25}$ Most studies have not been able to adjust for potential differences in health status and lifestyle distinguishing PPI users from nonusers, which may lead to biased associations. Thus, many studies have found an association between unhealthy traits, such as increased body mass index (BMI) scores, ${ }^{26-34}$ alcohol consumption, ${ }^{28,34,35}$ and smoking, ${ }^{33,34,36,37}$ and the risk of GERD, which is an important medical indication for PPI therapy. However, PPI use might be associated with increased health consciousness (frequent consultations with physicians, healthier lifestyle, etc) as is the case for the use of some other prophylactic drugs (eg, statins).

To the best of our knowledge, no study has provided data on health status and lifestyle among PPI users and nonusers in the general population. Such data are needed to evaluate uncontrolled confounding from lifestyle factors in observational PPI studies. Using data from a population-based health survey of 21,637 persons, linked to a nationwide Danish prescription database, we examined BMI, smoking habits, alcohol consumption, physical exercise habits, comorbidity, and diet in relation to PPI use.

\section{Materials and methods Setting}

Denmark has 5.6 million inhabitants and the country provides tax-financed universal access to free health services through the Danish National Health Service. Prescribed medications, including PPIs, are partially reimbursed. The National Health Service is coordinated across five administrative regions. The Central Danish Region is the second largest of these, with 1.25 million mixed rural and urban inhabitants.

\section{Study population}

The Danish Health Survey Hvordan har du det? [How are you?] based on self-reported questionnaires, is performed every fourth year. ${ }^{38}$ The How Are You? database contains participants' responses regarding lifestyle, diet, self-rated health, biometric measures, and diseases. Between January and March 2006, 31,500 persons living in the Central Danish Region were invited to participate. Eligible participants were Danish citizens, aged 25-79 years, identified using the nationwide Civil Registration System. A total of 21,637 persons (63\% of those invited) agreed to participate and completed a detailed questionnaire. ${ }^{38}$

\section{Lifestyle factors}

BMI was calculated as self-reported weight in kilograms, divided by self-reported height in meters squared. Scores were categorized according to World Health Organization criteria, as underweight (BMI <18.5), normal weight (BMI =18.5-24.99), overweight (BMI =25.00-29.99) and obesity (BMI $\geq 30$ ). Based on information about predominant type of diet (fat content and type, consumption of vegetables, fruits, bread, etc), respondents were divided into "healthy diet," "moderately healthy diet", and "unhealthy diet" groups. We defined "alcohol consumption" as either above or below the recommended maximum of 21 and 14 drinks weekly for men and women, respectively. "Smoking status" was categorized as "never," "former," or "current" (daily or occasional). Physical exercise was evaluated on the basis of a number of questions regarding the respondent's level of weekly activity (at least 30 minutes of strenuous workout, daily activity in terms of walking or cycling, or other work- or leisure-related physical activities). Responses were classified as regular physical exercise (yes/no).

\section{PPI use}

In all Danish medical registries, individuals are identified by means of their Civil Registration Number. This number is a unique identifier, assigned at birth, and stored in the Civil Registration System along with date of birth, residency status, dates of immigration/emigration, and death (if applicable). ${ }^{40}$ These identifiers allow unambiguous linkage of individuallevel data among medical registries.

The population-based National Prescription Registry records all prescriptions filled nationwide, linking the Civil Registration Number to prescription data, and includes type and quantity of drug dispensed according to the Anatomical Therapeutic Chemical Classification System. ${ }^{41}$ We used this system to identify all participants in the How Are You? survey who had received and filled a prescription for a PPI at any time before and up to 100 days after completing the survey questionnaire. PPI users were further divided into current PPI users (at least one recorded prescription for PPIs filled within 100 days before and up to 100 days after the survey date), and former PPI users (one or more PPI prescriptions filled more than 100 days before the survey date).

\section{Comorbidity and indications for PPI}

In Denmark, all International Classification of Diseases $(\mathrm{ICD} 10)^{42}$ hospital diagnoses and procedures are recorded, using patients' Civil Registration Numbers, in the Danish National Registry of Patients, which covers both inpatient stays and hospital clinic outpatient visits. ${ }^{43}$ We used the Charlson Comorbidity Index (CCI) to calculate a comorbidity score for each survey respondent. The CCI covers 19 major disease categories, weighted according to their prognostic impact on 
patient survival. ${ }^{44}$ We used the Danish National Registry of Patients to search for all ICD10 codes from 1977 onwards, then grouped PPI users and nonusers according to four levels of comorbidity: score 0 (no recorded comorbidity), 1 and 2 (moderate comorbidity), and $\geq 3$ (severe comorbidity). ${ }^{42}$ The distribution of comorbidity scores is shown in Table 1. We assessed respondents' medical history of the following medical indications for PPI use separately: esophagitis (K20), gastroesophageal reflux (K21), esophageal erosion or ulcer (K22.1A-K22.1B), gastric ulcer (K25), duodenal ulcer (K26), gastro-duodenal ulcer (K27), and gastro-duodenitis (K29).

\section{Statistical analysis}

We estimated the prevalence of demographic variables, comorbidities, and lifestyle factors according to ever use or nonuse of PPIs. We then calculated prevalence ratios (PRs) for lifestyle factors, comparing PPI users and nonusers directly age- and sex-standardized to the cohort of all participants. All ratios were reported with a $95 \%$ confidence interval (CI). We repeated the analyses for current PPI users and former PPI users. We also calculated standardized PRs for lifestyle factors, comparing PPI users and nonusers within the subgroups of participants who all had a medical history of esophagitis, gastroesophageal reflux, or peptic ulcer. Statistical analyses were performed using SAS software (v 9.2; SAS Institute Inc., Cary, NC, USA). The Danish Registry Board approved the study (record number 2009-41-3866).

Table I Demographic factors and comorbidities associated with ever use of proton pump inhibitors among 21,637 persons aged 25-79 years who participated in the Hvordan har du det? [How are you?] ${ }^{38}$ survey study in the Central Danish Region, 2006

\begin{tabular}{|c|c|c|}
\hline Characteristic & $\begin{array}{l}\text { Ever use, } \\
n=3,047(14.1 \%)\end{array}$ & $\begin{array}{l}\text { Never use, } \\
n=\mid 8,590(85.9 \%)\end{array}$ \\
\hline \multicolumn{3}{|l|}{ Age, years } \\
\hline Under 40 & $464(15.2 \%)$ & $4,667(25.1 \%)$ \\
\hline $40-49$ & $549(18.0 \%)$ & $4,303(23.2 \%)$ \\
\hline $50-59$ & $702(23.0 \%)$ & $4,283(23.0 \%)$ \\
\hline $60-69$ & $779(25.6 \%)$ & $3,485(18.8 \%)$ \\
\hline $70+$ & $553(18.0 \%)$ & $1,852(10.0 \%)$ \\
\hline \multicolumn{3}{|l|}{ Sex } \\
\hline Female & $\mathrm{I}, 69 \mathrm{I}(55.5 \%)$ & $9,817(52.8 \%)$ \\
\hline Male & $\mathrm{I}, 356(45.5 \%)$ & $8,773(47.2 \%)$ \\
\hline \multicolumn{3}{|c|}{ Charlson comorbidity index score } \\
\hline 0 & I,982 (65. I\%) & $|5,83|(85.2 \%)$ \\
\hline 1 & $523(17.2 \%)$ & $\mathrm{I}, 504(8.1 \%)$ \\
\hline 2 & $309(10.1 \%)$ & $910(4.9 \%)$ \\
\hline $3+$ & $233(7.7 \%)$ & $345(1.9 \%)$ \\
\hline \multicolumn{3}{|c|}{ Hospital history of reflux, esophagitis, or ulcer diagnosis } \\
\hline No & $2,567(84.3 \%)$ & $18,433(99.16 \%)$ \\
\hline Yes & $480(15.8 \%)$ & I 57 (0.84\%) \\
\hline
\end{tabular}

Note: Missing values are not shown.

\section{Results}

Among survey respondents, 1,356 (13.4\%) males and 1,691 (14.7\%) females reported PPI use. Table 1 describes PPI use by age, sex, and comorbidity level. Compared with nonusers, PPI users were older (median age $=57$ vs 50 years) and slightly more were female. Among PPI users, $35 \%$ had a CCI score of 1 or more, compared with only $15 \%$ among nonusers.

Among the 637 (3\%) persons in the survey cohort who had previous hospital-diagnosed esophagitis, gastroesophageal reflux, or peptic ulcer, $75 \%$ (480 persons) were in the PPI-exposed group. This corresponds to prevalence rates of $16 \%$ for these medical indications among PPI users and 1\% among nonusers (Table 1).

While approximately $1 \%-3 \%$ of survey response answers were missing for the various lifestyle questions, the proportion of missing answers was very similar for PPI users and nonusers. One exception was data on alcohol consumption data, which were missing for $8.3 \%$ of the PPI users and $13.2 \%$ of the nonusers (Table 2).

\section{$\mathrm{BMI}$}

In the cohort as a whole, 7,724 persons (35.7\%) reported overweight (BMI $=25-30)$ and 2,951 (13.4\%) reported obesity (BMI >30). In general, more males (44\%-47\%) were overweight than females (27\%-29\%) among both PPI users and nonusers, whereas in the obese category no major difference was seen between sexes. More PPI users were obese than nonusers (16.7\% vs $13.1 \%$, Table 2$)$. After standardizing for differences in sex and age, PPI users had an unaltered higher prevalence of obesity (standardized prevalence $=16.6 \%$ [95\% CI: $15.2 \%-18.0 \%]$ ) than nonusers (standardized prevalence $=13.2 \%$ [95\% CI: $12.7 \%-13.7 \%]$ ), corresponding to a standardized PR of 1.3 (95\% CI: 1.2-1.4). No major differences were seen in the other weight categories.

\section{Diet and exercise}

We observed an increased standardized PR (1.2 [95\% CI: 1.1-1.3]) for unhealthy diets among PPI users compared with nonusers. Among both PPI users and nonusers, only one-third undertook regular exercise. The standardized PR for exercise among PPI users was 0.9 (95\% CI: 0.9-1.0).

\section{Smoking and alcohol}

The number of current smokers $(25.1 \%$ vs $22.4 \%)$ and previous smokers $(41.0 \%$ vs $32.0 \%)$ was higher among PPI users than nonusers. The corresponding PRs among PPI users were 1.2 (95\% CI: 1.1-1.3) for current smoking and 
Table 2 Prevalence and standardized prevalence ratios (PRs) for various lifestyle factors among ever users of proton pump inhibitors (PPIs) compared with never users of PPIs

\begin{tabular}{|c|c|c|c|}
\hline Characteristic & $\begin{array}{l}\text { Crude prevalence, } \\
\text { ever PPI use, n=3,047 }\end{array}$ & $\begin{array}{l}\text { Crude prevalence, } \\
\text { never PPI use, } n=\mid 8,590\end{array}$ & $\begin{array}{l}\text { Standardized PR,* ever } \\
\text { vs never use of PPIs }(95 \% \mathrm{Cl})\end{array}$ \\
\hline \multicolumn{4}{|l|}{ BMI } \\
\hline Underweight & 47 (1.5\%) & 265 (I.4\%) & I.0 (0.7-I.4) \\
\hline Normal weight & $\mathrm{I}, 280$ (42.0\%) & $8,862(47.7 \%)$ & $0.9(0.8-0.9)$ \\
\hline Overweight & I, 137 (37.3\%) & 6,587 (35.4\%) & I.I (I.0-I.I) \\
\hline Obese & $508(16.7 \%)$ & 2,443 (I3.1\%) & $1.3(1.2-1.4)$ \\
\hline Missing & 75 (2.5\%) & $433(2.3 \%)$ & - \\
\hline \multicolumn{4}{|l|}{ Diet } \\
\hline Healthy & $632(20.7 \%)$ & 3,901 (21.0\%) & $0.9(0.9-1.0)$ \\
\hline Moderately healthy & $\mathrm{I}, 872$ (6I.4\%) & II,852 (63.6\%) & $1.0(0.9-1.0)$ \\
\hline Unhealthy & 446 (I4.6\%) & 2,434 (13.1\%) & $1.2(||-.\mid .3)$ \\
\hline Missing & 97 (3.2\%) & $403(2.2 \%)$ & - \\
\hline \multicolumn{4}{|l|}{ Exercise } \\
\hline Regular & I,22I (40.I\%) & 8,468 (45.6\%) & $0.9(0.9-1.0)$ \\
\hline Not regular & I,746 (57.3\%) & $9,740(52.4 \%)$ & I.I (I.0-I.I) \\
\hline Missing & $80(2.6 \%)$ & $382(2.0 \%)$ & - \\
\hline \multicolumn{4}{|l|}{ Tobacco smoking } \\
\hline Current smoker & 764 (25.1\%) & 4,169 (22.4\%) & I.2(I.I-I.3) \\
\hline Former smoker & I,250 (4I.0\%) & $5,949(32.0 \%)$ & I.2 (I.I-I.2) \\
\hline Never smoker & 989 (32.5\%) & 8,307 (44.7\%) & $0.8(0.7-0.8)$ \\
\hline Missing & $44(\mathrm{I} .4 \%)$ & 165 (0.9\%) & - \\
\hline \multicolumn{4}{|l|}{ Alcohol intake } \\
\hline$>|4|>2 \mid$ weekly drinks for women/men & $16.9(16.9 \%)$ & $3,080(16.6 \%)$ & I.0 (0.9-I.I) \\
\hline$\leq|4 / \leq 2|$ weekly drinks for women/men & $2,129(69.9 \%)$ & $13,974(75.2 \%)$ & $1.0(0.9-1.0)$ \\
\hline Missing & $402(13.2 \%)$ & I,536 (8.3\%) & - \\
\hline
\end{tabular}

Note: *Standardized to the distribution of age and gender in the total study population. Abbreviations: $\mathrm{BMI}$, body mass index; $\mathrm{Cl}$, confidence interval.

1.2 (95\% CI: 1.1-1.2) for previous smoking (Tables 2 and 3). There was little difference in overall alcohol consumption between the two groups, with $16.6 \%$ (95\% CI: 16.0\%-17.1\%) of PPI users and $16.9 \%$ (95\% CI: $15.3 \%-18.9 \%$ ) of nonusers exceeding recommended weekly alcohol consumption, yielding a standardized PR of 1.0 (95\% CI: 0.9-1.1).

\section{Sub-analyses for current versus former PPI use and medical indications for PPIs}

In general, we observed similar lifestyle associations with PPI use among current and former PPI users (Table 3).

When we restricted our analyses to persons with a hospital history of medical indication for PPI use (esophagitis, gastroesophageal reflux, or peptic ulcer), the associations between PPI use and an increased BMI were similarly strong, as in the overall cohort. Thus, standardized PRs among PPI users were 1.4 (95\% CI: 0.8-2.2) for obesity and 1.4 (95\% CI: $1.0-1.9)$ for overweight. In contrast, the PRs for current and former smoking associated with PPI use in the medical indication sub-cohort were lower than in the overall cohortthat is, close to 1.0. PRs for the other lifestyle factors were similar to those for the overall cohort.

\section{Discussion}

This study of more than 20,000 participants in a populationbased survey found that the prevalence of obesity, smoking, comorbidity, and, to a lesser degree, unhealthy diet was higher among PPI users than among persons who never used PPIs. To our knowledge, this is the first populationbased study evaluating lifestyle characteristics in PPI users compared with nonusers, based on population comparisons after controlling for age and sex differences.

Our finding that more than one-third of PPI users were either overweight or obese, with PPI users more obese than nonusers is in accordance with earlier research showing that high BMI is a major risk factor for gastroesophageal reflux, which in turn is the main indication for prescribing PPIs. ${ }^{26-34}$ Further, when we restricted our analysis to persons with a hospital-diagnosed indication for PPI use, we still found that PPI users were more obese than nonusers. In a recent study of 726 PPI users in the UK, the proportion of overweight or obese patients was $67.5 \% .{ }^{45}$ Similarly, a recent report based on Nurses' Health Study data found PPI users to have both a higher BMI and be less physically active than PPI nonusers. ${ }^{25}$ In contrast, a study of PPI use and risk of hip 
Table 3 Prevalence and standardized prevalence ratios (PRs) for various lifestyle factors among current and former proton pump inhibitor (PPI) users compared with never users of PPIs

\begin{tabular}{|c|c|c|c|c|}
\hline Characteristic & $\begin{array}{l}\text { Crude prevalence, } \\
\text { current use of PPIs, } \\
n=I, I 79\end{array}$ & $\begin{array}{l}\text { Standardized PR,* } \\
\text { current vs never use } \\
\text { of PPIs }(95 \% \mathrm{CI})\end{array}$ & $\begin{array}{l}\text { Crude prevalence, } \\
\text { former use of PPIs, } \\
n=1,868\end{array}$ & $\begin{array}{l}\text { Standardized PR,* } \\
\text { former vs never use } \\
\text { of PPIs }(95 \% \mathrm{Cl})\end{array}$ \\
\hline \multicolumn{5}{|l|}{ BMI } \\
\hline Underweight & 17 (1.4\%) & I.I (0.7-I.9) & 30 (1.6\%) & $0.9(0.6-1.4)$ \\
\hline Normal weight & 449 (38.8\%) & $0.9(0.8-0.9)$ & 831 (44.9\%) & $1.0(0.9-1.0)$ \\
\hline Overweight & 459 (38.1\%) & $1.0(0.9-1.1)$ & $678(36.3 \%)$ & $1.0(0.9-1.1)$ \\
\hline Obese & $220(18.7 \%)$ & I.4 (I.2-I.7) & 288 (15.4\%) & $1.2(1.0-1.3)$ \\
\hline \multicolumn{5}{|l|}{ Exercise } \\
\hline Regular & $438(37.2 \%)$ & $0.8(0.8-0.9)$ & $783(41.9 \%)$ & $1.0(0.9-1.0)$ \\
\hline Not regular & $713(60.5 \%)$ & I.I (I.I-I.2) & I,033 (55.3\%) & $1.0(1.0-1.1)$ \\
\hline \multicolumn{5}{|l|}{ Diet } \\
\hline Healthy & $250(21.2 \%)$ & $0.9(0.8-1.1)$ & $382(20.5 \%)$ & $1.0(0.9-1.1)$ \\
\hline Moderately healthy & $713(60.5 \%)$ & $1.0(0.9-1.0)$ & $1,159(62.0 \%)$ & $1.0(0.9-1.0)$ \\
\hline Unhealthy & I 74 (I4.8\%) & I.2(I.0-I.4) & $272(14.6 \%)$ & I.I (I.0-I.3) \\
\hline \multicolumn{5}{|l|}{ Tobacco smoking } \\
\hline Current smoker & 287 (24.3\%) & I.I (I.0-I.2) & 477 (25.5\%) & I.I (I.0-I.3) \\
\hline Former smoker & $517(43.9 \%)$ & $1.2(1.1-1.3)$ & $733(39.2 \%)$ & I.I (I.0-I.2) \\
\hline Never smoker & $355(30.1 \%)$ & $0.7(0.7-0.8)$ & 634 (33.9\%) & $0.8(0.7-0.9)$ \\
\hline \multicolumn{5}{|l|}{ Alcohol intake } \\
\hline$>|4|>2 \mid$ weekly drinks for women/men & $215(18.2 \%)$ & I.0 (0.9-I.I) & $247(\mid 3.2 \%)$ & $0.9(0.8-1.0)$ \\
\hline$\leq|4| \leq 2 \mid$ weekly drinks for women/men & $809(68.6 \%)$ & $1.0(0.9-1.0)$ & I,320 (70.6\%) & $1.0(0.9-1.0)$ \\
\hline
\end{tabular}

Notes: *Standardized to age and sex in the total study population. Missing values are not shown. Abbreviations: $\mathrm{BMI}$, body mass index; $\mathrm{Cl}$, confidence interval.

fractures reported no difference in either BMI or smoking habits between PPI users and nonusers. ${ }^{46}$ In our study, both current and previous smoking were more prevalent among PPI users than among nonusers. This accords with a number of previous studies of which many reported odds ratios of $\sim 2$ for an association between smoking and risk of reflux symptoms. ${ }^{31,34,36,37,46,47}$

We did not observe an association between ever use of PPIs and overall alcohol consumption. Conflicting reports have been published about the association between alcohol consumption and risk of reflux symptoms, and some studies found such an association only for selected types of alcohol. ${ }^{28,34,37,48,49}$

We found no association between physical exercise habits and PPI use. Absence of an association between exercise and reflux symptoms has been found in some questionnaire studies, ${ }^{49,50}$ whereas two recent population-based studies found a lower prevalence of GERD symptoms among persons who exercised regularly. ${ }^{34,37}$ Some studies have suggested that physical exercise may increase the amount of transient lower esophageal sphincter relaxation, thereby possibly diminishing any positive effect of regular exercise on GERD. ${ }^{48}$

Previous data on dietary habits among PPI users are scarce. Published results have been conflicting concerning unhealthy diet as a possible risk factor for GERD. Some studies found no association between dietary fat intake and
GERD, ${ }^{34,49}$ whereas other studies are compatible with an association between high intake of dietary fat and reflux symptoms. ${ }^{51}$ Further studies are needed to clarify this association.

It is evident from our data that patients prescribed PPIs have substantially more comorbidity than nonusers. Previous studies in reflux patients have reported similar findings, ${ }^{52,53}$ and a recent study performed at our institution showed marked comorbidity differences between controls and reflux patients. ${ }^{54}$ Thus, comorbidity should be taken into account when designing and interpreting studies involving reflux patients or PPI users.

\section{Strengths and limitations}

The main strengths of our study are its comparatively large size, yielding precise risk estimates, and the use of independent population-based and highly valid registries for assessing PPI use and comorbidity, minimizing the possibility of recall and investigator bias as compared with other studies. A study limitation is the response rate of $63 \%$ in the survey, so generalizations of our findings should be made with caution. Further, persons who choose to participate in a survey may have a different risk factor profile and better health than those who decline. ${ }^{55}$ However, this is likely to apply to both PPI users and nonusers, and thus would not bias the relative estimates we report. Another study limitation is its 
cross-sectional design, which makes it uncertain whether PPI use preceded lifestyle changes or vice versa. However, our main objective was to examine lifestyle differences among PPI users and nonusers, rather than to make inferences about the causal mechanisms.

\section{Conclusion}

This cross-sectional study among health survey respondents found that persons who use PPIs are more obese, smoke more, tend to follow a less healthy diet, and have more comorbidity than nonusers. These data may be useful when estimating the amount of uncontrolled confounding from lifestyle factors in observational studies of reflux patients and of PPI effects.

\section{Acknowledgment}

The authors acknowledge Henrik T Sorensen for his contribution in the planning of this study.

\section{Disclosure}

This study was supported by the Institute of Clinical Medicine and Department of Clinical Epidemiology, Aarhus University, Aarhus, Denmark. The sponsors played no role in the study design, data collection, data analysis, data interpretation, or writing of the report. Frederik Hvid-Jensen, Rikke B Nielsen, Lars Pedersen, Peter Funch-Jensen, Asbjørn M Drewes, Finn B Larsen, and Reimar W Thomsen declare no conflicts of interest in this work.

\section{References}

1. Moayyedi P, Delaney BC, Vakil N, Forman D, Talley NJ. The efficacy of proton pump inhibitors in nonulcer dyspepsia: a systematic review and economic analysis. Gastroenterology. 2004;127(5):1329-1337.

2. Hillman LC, Chiragakis L, Shadbolt B, Kaye GL, Clarke AC. Protonpump inhibitor therapy and the development of dysplasia in patients with Barrett's oesophagus. Med J Aust. 2004;180(8):387-391.

3. Edwards SJ, Lind T, Lundell L, Das R. Systematic review: standard- and double-dose proton pump inhibitors for the healing of severe erosive oesophagitis - a mixed treatment comparison of randomized controlled trials. Aliment Pharmacol Ther. 2009;30(6):547-556.

4. Donnellan C, Sharma N, Preston C, Moayyedi P. Medical treatments for the maintenance therapy of reflux oesophagitis and endoscopic negative reflux disease. Cochrane Database Syst Rev. 2005;(2):CD003245.

5. Cremonini F, Wise J, Moayyedi P, Talley NJ. Diagnostic and therapeutic use of proton pump inhibitors in non-cardiac chest pain: a metaanalysis. Am J Gastroenterol. 2005;100(6):1226-1232.

6. Lööf L, Götell P, Elfberg B. The incidence of reflux oesophagitis. A study of endoscopy reports from a defined catchment area in Sweden. Scand J Gastroenterol. 1993;28(2):113-118.

7. Valle C, Broglia F, Pistorio A, Tinelli C, Perego M. Prevalence and impact of symptoms suggestive of gastroesophageal reflux disease. Dig Dis Sci. 1999;44(9):1848-1852.

8. Sontag SJ, Sonnenberg A, Schnell TG, Leya J, Metz A. The long-term natural history of gastroesophageal reflux disease. J Clin Gastroenterol. 2006;40(5):398-404.
9. Dent J, El-Serag HB, Wallander MA, Johansson S. Epidemiology of gastro-oesophageal reflux disease: a systematic review. Gut. 2005;54(5): 710-717.

10. Mehta S, Bennett J, Mahon D, Rhodes M. Prospective trial of laparoscopic nissen fundoplication versus proton pump inhibitor therapy for gastroesophageal reflux disease: Seven-year follow-up. J Gastrointest Surg. 2006;10(9):1312-1316; discussion 1316-1317.

11. Mahon D, Rhodes M, Decadt B, et al. Randomized clinical trial of laparoscopic Nissen fundoplication compared with proton-pump inhibitors for treatment of chronic gastro-oesophageal reflux. Br J Surg. 2005;92(6):695-699.

12. Spechler SJ, Lee E, Ahnen D, et al. Long-term outcome of medical and surgical therapies for gastroesophageal reflux disease: follow-up of a randomized controlled trial. JAMA. 2001;285(18):2331-2338.

13. Lundell L, Miettinen P, Myrvold HE, et al; Nordic GERD Study Group. Comparison of outcomes twelve years after antireflux surgery or omeprazole maintenance therapy for reflux esophagitis. Clin Gastroenterol Hepatol. 2009;7(12):1292-1298; quiz 1260.

14. Anvari M, Allen C, Marshall J, et al. A randomized controlled trial of laparoscopic nissen fundoplication versus proton pump inhibitors for treatment of patients with chronic gastroesophageal reflux disease: One-year follow-up. Surg Innov. 2006;13(4):238-249.

15. Lundell L, Attwood S, Ell C, et al; LOTUS trial collaborators. Comparing laparoscopic antireflux surgery with esomeprazole in the management of patients with chronic gastro-oesophageal reflux disease: a 3-year interim analysis of the LOTUS trial. Gut. 2008;57(9):1207-1213.

16. IMS Health Incorporated. Top 20 Global Therapeutic Classes, 2010, Toal Audited Markets. Danbury, CT: IMS Health Incorporated; 2010. Available at: http://www.imshealth.com/deployedfiles/imshealth/Global/ Content/StaticFile/Top_Line_Data/Top_20_Global_Therapy_Classes. pdf. Accessed September 16, 2013.

17. Nardino RJ, Vender RJ, Herbert PN. Overuse of acid-suppressive therapy in hospitalized patients. Am J Gastroenterol. 2000;95(11):3118-3122.

18. Batuwitage BT, Kingham JG, Morgan NE, Bartlett RL. Inappropriate prescribing of proton pump inhibitors in primary care. Postgrad Med J. 2007;83(975):66-68.

19. Laine L, Hennekens C. Proton pump inhibitor and clopidogrel interaction: fact or fiction? Am J Gastroenterol. 2010;105(1):34-41.

20. Thomson AB, Sauve MD, Kassam N, Kamitakahara H. Safety of the long-term use of proton pump inhibitors. World J Gastroenterol. 2010;16(19):2323-2330.

21. Johnson DA. Safety of proton pump inhibitors: current evidence for osteoporosis and interaction with antiplatelet agents. Curr Gastroenterol Rep. 2010;12(3):167-174.

22. Tepeš B. Long-term acid inhibition: benefits and harms. Dig Dis. 2011;29(5):476-481.

23. O’Donoghue ML, Braunwald E, Antman EM, et al. Pharmacodynamic effect and clinical efficacy of clopidogrel and prasugrel with or without a proton-pump inhibitor: an analysis of two randomised trials. Lancet. 2009;374(9694):989-997.

24. Targownik LE, Lix LM, Metge CJ, Prior HJ, Leung S, Leslie WD. Use of proton pump inhibitors and risk of osteoporosis-related fractures. CMAJ. 2008;179(4):319-326.

25. Khalili H, Huang ES, Jacobson BC, Carmargo CA Jr, Feskanich D, Chan AT. Use of proton pump inhibitors and risk of hip fracture in relation to dietary and lifestyle factors: a prospective cohort study. BMJ. 2012;344:e372.

26. Hampel H, Abraham NS, El-Serag HB. Meta-analysis: obesity and the risk for gastroesophageal reflux disease and its complications. Ann Intern Med. 2005;143(3):199-211.

27. Wajed SA, Streets CG, Bremner CG, DeMeester TR. Elevated body mass disrupts the barrier to gastroesophageal reflux. Arch Surg. 2001;136(9):1014-1019.

28. Locke GR 3rd, Talley NJ, Fett SL, Zinsmeister AR, Melton LJ 3rd. Risk factors associated with symptoms of gastroesophageal reflux. Am J Med. 1999;106(6):642-649. 
29. Oliveria SA, Christos PJ, Talley NJ, Dannenberg AJ. Heartburn risk factors, knowledge, and prevention strategies: a population-based survey of individuals with heartburn. Arch Intern Med. 1999;159(14): 1592-1598.

30. Stanghellini V. Three-month prevalence rates of gastrointestinal symptoms and the influence of demographic factors: results from the Domestic/International Gastroenterology Surveillance Study (DIGEST). Scand J Gastroenterol Suppl. 1999;231:20-28.

31. Murray L, Johnston B, Lane A, et al. Relationship between body mass and gastro-oesophageal reflux symptoms: The Bristol Helicobacter Project. Int J Epidemiol. 2003;32(4):645-650.

32. Nilsson M, Johnsen R, Ye W, Hveem K, Lagergren J. Obesity and estrogen as risk factors for gastroesophageal reflux symptoms. JAMA. 2003;290(1):66-72.

33. Zheng Z, Nordenstedt H, Pedersen NL, Lagergren J, Ye W. Lifestyle factors and risk for symptomatic gastroesophageal reflux in monozygotic twins. Gastroenterology. 2007;132(1):87-95.

34. Nocon M, Labenz J, Willich SN. Lifestyle factors and symptoms of gastro-oesophageal reflux - a population-based study. Aliment Pharmacol Ther. 2006;23(1):169-174.

35. Vitale GC, Cheadle WG, Patel B, Sadek SA, Michel ME, Cuschieri A. The effect of alcohol on nocturnal gastroesophageal reflux. JAMA. 1987;258(15):2077-2079.

36. Kahrilas PJ, Gupta RR. Mechanisms of acid reflux associated with cigarette smoking. Gut. 1990;31(1):4-10.

37. Nilsson M, Johnsen R, Ye W, Hveem K, Lagergren J. Lifestyle related risk factors in the aetiology of gastro-oesophageal reflux. Gut. 2004;53(12):1730-1735.

38. Larsen FB. Hvordan har du det? Selvvurderet helbred og ulighed $i$ sundhed [How are you? Self-rated health and social inequality in health]. Aarhus: Unit of Health Promotion, Department of Public Health; 2003.

39. Health DNBo. Danish National Board of Health; 2011. Available at: http://www.sst.dk/Sundhed\%20og\%20forebyggelse/Alkohol.aspx. Accessed October 10, 2013.

40. Pedersen CB, Gøtzsche H, Møller JO, Mortensen PB. The Danish Civil Registration System. A cohort of eight million persons. Dan Med Bull. 2006;53(4):441-449. Available from: http:/www.whocc.no/ atc_ddd_index/.Accessed October 10, 2013.

41. World Health Organization. ATC/DDD Classification. WHO Drug Information. 2001;15:84-88. Available from: http:/www.whocc.no/ atc_ddd_index/.Accessed October 10, 2013.

42. World Health Organization. International Statistical Classification of Diseases and Related Health Problems 10th Revision. Available from: http://apps.who.int/classifications/icd10/browse/2010/en. Accessed October 10, 2013.
43. Lynge E, Sandegaard JL, Rebolj M. The Danish National Patient Register. Scand J Public Health. 2011;39(Suppl 7):30-33.

44. Charlson ME, Pompei P, Ales KL, MacKenzie CR. A new method of classifying prognostic comorbidity in longitudinal studies: development and validation. J Chronic Dis. 1987;40(5):373-383.

45. Raghunath AS, Hungin AP, Mason J, Jackson W. Symptoms in patients on long-term proton pump inhibitors: prevalence and predictors. Aliment Pharmacol Ther. 2009;29(4):431-439.

46. Kaye JA, Jick H. Proton pump inhibitor use and risk of hip fractures in patients without major risk factors. Pharmacotherapy. 2008;28(8): 951-959.

47. Moayyedi P, Talley NJ. Gastro-oesophageal reflux disease. Lancet. 2006;367(9528):2086-2100.

48. Lagergren J, Bergström R, Nyrén O. No relation between body mass and gastro-oesophageal reflux symptoms in a Swedish population based study. Gut. 2000;47(1):26-29.

49. Meining A, Classen M. The role of diet and lifestyle measures in the pathogenesis and treatment of gastroesophageal reflux disease. Am J Gastroenterol. 2000;95(10):2692-2697.

50. Nandurkar S, Locke GR 3rd, Fett S, et al. Relationship between body mass index, diet, exercise and gastro-oesophageal reflux symptoms in a community. Aliment Pharmacol Ther. 2004;20(5):497-505.

51. Dore MP, Maragkoudakis E, Fraley K, et al. Diet, lifestyle and gender in gastro-esophageal reflux disease. Dig Dis Sci. 2008;53(8): 2027-2032.

52. El-Serag HB, Satia JA, Rabeneck L. Dietary intake and the risk of gastro-oesophageal reflux disease: a cross sectional study in volunteers. Gut. 2005;54(1):11-17.

53. Hansen JM, Wildner-Christensen M, Schaffalitzky de Muckadell OB. Gastroesophageal reflux symptoms in a Danish population: a prospective follow-up analysis of symptoms, quality of life, and health-care use. Am J Gastroenterol. 2009;104(10):2394-2403.

54. Hvid-Jensen F, Pedersen L, Munk EM, Drewes AM, Funch-Jensen P. Long-term complications to reflux disease in community practice. A 17-year cohort study of 4706 patients. Scand J Gastroenterol. 2011; 46(10):1179-1186.

55. Ronkainen J, Aro P, Storskrubb T, et al. Gastro-oesophageal reflux symptoms and health-related quality of life in the adult general population - the Kalixanda study. Aliment Pharmacol Ther. 2006;23(12): 1725-1733.
Clinical Epidemiology

\section{Publish your work in this journal}

Clinical Epidemiology is an international, peer-reviewed, open access journal focusing on disease and drug epidemiology, identification of risk factors and screening procedures to develop optimal preventative initiatives and programs. Specific topics include: diagnosis, prognosis, treatment, screening, prevention, risk factor modification, systematic

\section{Dovepress}

reviews, risk \& safety of medical interventions, epidemiology \& biostatical methods, evaluation of guidelines, translational medicine, health policies \& economic evaluations. The manuscript management system is completely online and includes a very quick and fair peer-review system, which is all easy to use. 